\title{
Geographic variation in health insurance benefits in Qianjiang District, China: a cross-sectional study
}

\author{
Yue Wu, Liang Zhang, Xuejiao Liu, Ting Ye ${ }^{*}$ (1) and Yongfei Wang
}

\begin{abstract}
Background: Health insurance contributes to reducing the economic burden of disease and improving access to healthcare. In 2016, the Chinese government announced the integration of the New Cooperative Medical Scheme (NCMS) and Urban Resident Basic Medical Insurance (URBMI) to reduce system segmentation. Nevertheless, it was unclear whether there would be any geographic variation in health insurance benefits if the two types of insurance were integrated. The aim of this study was to identify the potential geographic variation in health insurance benefits and the related contributing factors.

Methods: This cross-sectional study was carried out in Qianjiang District, where the NCMS and URBMI were integrated into Urban and Rural Resident Basic Medical Insurance Scheme (URRBMI) in 2010. All beneficiaries under the URRBMI were hospitalized at least once in 2013, totaling 445,254 persons and 65,877 person-times, were included in this study. Town-level data on health insurance benefits, healthcare utilization, and socioeconomic and geographical characteristics were collected through health insurance system, self-report questionnaires, and the 2014 Statistical Yearbook of Qianjiang District. A simplified Theil index at town level was calculated to measure geographic variation in health insurance benefits. Colored maps were created to visualize the variation in geographic distribution of benefits. The effects of healthcare utilization and socioeconomic and geographical characteristics on geographic variation in health insurance benefits were estimated with a multiple linear regression analysis.

Results: Different Theil index values were calculated for different towns, and the Theil index values for compensation by person-times and amount were 2.5028 and 1.8394 in primary healthcare institutions and 1.1466 and 0.9204 in secondary healthcare institutions. Healthcare-seeking behavior and economic factors were positively associated with health insurance benefits in compensation by person-times significantly, meanwhile, geographical accessibility and economic factors had positive effects $(p<0.05)$.
\end{abstract}

Conclusions: The geographic variation in health insurance benefits widely existed in Qianjiang District and the distribution of health insurance benefits for insured inpatients in primary healthcare institutions was distinctly different from that in secondary healthcare institutions. When combining the NRCM and URMIS in China, the geographical accessibility, healthcare-seeking behavior and economic factors required significant attention.

Keywords: Health insurance, Universal health coverage, Geographic variation, Theil index, Geographic information system, Cross-sectional study

\footnotetext{
* Correspondence: yeting868@163.com

School of Medicine and Health Management, Tongji Medical College,

Huazhong University of Science and Technology, 13 Hangkong Road,

Wuhan, China
} 


\section{Background}

Health insurance has emerged as the main approach to improving financial risk protection and access to quality healthcare [1-3]. In 2005, all WHO member states made a commitment to achieve universal health coverage, which is a collective expression of the belief that all people should have access to healthcare services without risk of financial ruin [4]. Numerous countries have taken measures to improve universal health coverage and have made great progress, such as Mexico [5] and Rwanda [6].

In China, health insurance has nearly reached universal coverage, covering more than $98 \%$ of individuals. However, segmentation has been severe for a long time among New Cooperative Medical Scheme (NCMS), Urban Resident Basic Medical Insurance (URBMI), and Urban Employee Basic Medical Insurance (UEBMI) which cover different population groups. These three identity-based, district-varied health schemes have led to rural-urban variation in health insurance and have affected access to healthcare [7]. Furthermore, there are also great disparities in the reimbursements [8]. Considering the serious segmentation of the health insurance system and in order to improve the equity, sustainability and efficiency of NCMS and URBMI, the decision to integrate the NCMS and URBMI was announced in China in 2016 [9].

However, it is unclear whether the integration of NCMS and URBMI has impacted geographic variation in medical services utilization. It refers to variation of medical services use of a population according to the geographically defined unit [10]. Geographic variation in medical services utilization is explained by both patient characteristics and supplier characteristics and has remained a major topic in research field. It is generally known that gaps in economic development may affect the utilization of medical services, residents with higher income and educational status may utilize more healthcare services than others [11]. And geographical accessibility is one of the possible determinants of medical services utilization [12-14]. In this study, we exploited geographic variation in health insurance benefits to reflect the geographic variation in medical services utilization.

Since John Snow first considered geographic variations in health by mapping the location of cholera cases around water pumps in mid-1800s, numerous studies have been conducted on geographic variation in at least four aspects of health. Firstly, many studies examined variation in the geographic distribution of diseases, including prevalence or incidence rate, as well as the survival and mortality rates of several diseases [15-20]. Secondly, some studies focused on health resource allocation. In 1999, Mick SS et al. studied the geographic distribution of medical graduates [21]. Thirdly, some researchers investigated geographic variation in healthcare services, including cancer screening or other services [22-25]. Fourthly, some studies examined geographic variation in healthcare expenses [26-29]. By analyzing the medication information of the elderly under Medicare Part D, Zhang Y et al. concluded that the geographic variation in prescription safety was larger than that in drug spending and that there was no association between high drug spending and medical care quality [30, 31].

To determine whether there will be any obvious geographic variation in health insurance benefits worth studying upon the integration of NCMS and URBMI. We conducted a cross-sectional study in Qianjiang District in China in 2013, where NCMS and URBMI were integrated into a basic medical insurance called the Urban and Rural Resident Basic Medical Insurance Scheme (URRBMI) in 2010, to shed light on this issue as well as to provide evidence for health insurance integration. This study aimed to identifying geographic variations in health insurance benefits and the contributing factors. We had three overall objectives in the current study: (1) to produce a descriptive analysis of variation in health insurance benefits; (2) to map the geographic distribution of variation in health insurance benefits; and (3) to analyze the potential factors influencing geographic variation in health insurance benefits.

\section{Methods}

\section{Study setting and sample}

A cross-sectional study was conducted in Qianjiang District in China in 2013. Our study sample comprises all beneficiaries under the URRBMI who were hospitalized at least once in 2013, totaling 445,254 persons and 65,877 admissions. In this study, primary healthcare institutions consist of all township health institutions, community health centers and other clinics. Other hospitals are classified as secondary healthcare institutions. In this district, as shown in Fig. 1, the urban areas include Chengdong, Chengxi, Chengnan, Zhengyang, Zhoubai, and Zhuoshui. The district center represents Chengdong, Chengxi, and Chengnan. There are several arterial roads, primarily north-south highways (G319, G65).

\section{Unit of analysis}

Based on previous studies of geographic variation, administrative units have frequently been used for geographic variation studies [10, 26]. Furthermore, Verena Vogt et al., who examined geographic variation in the use of cancer screening at the district level, proposed that analysis on a smaller geographical scale could result in more reliable conclusions [32]. Therefore, we analyzed data at the town level in this study. 


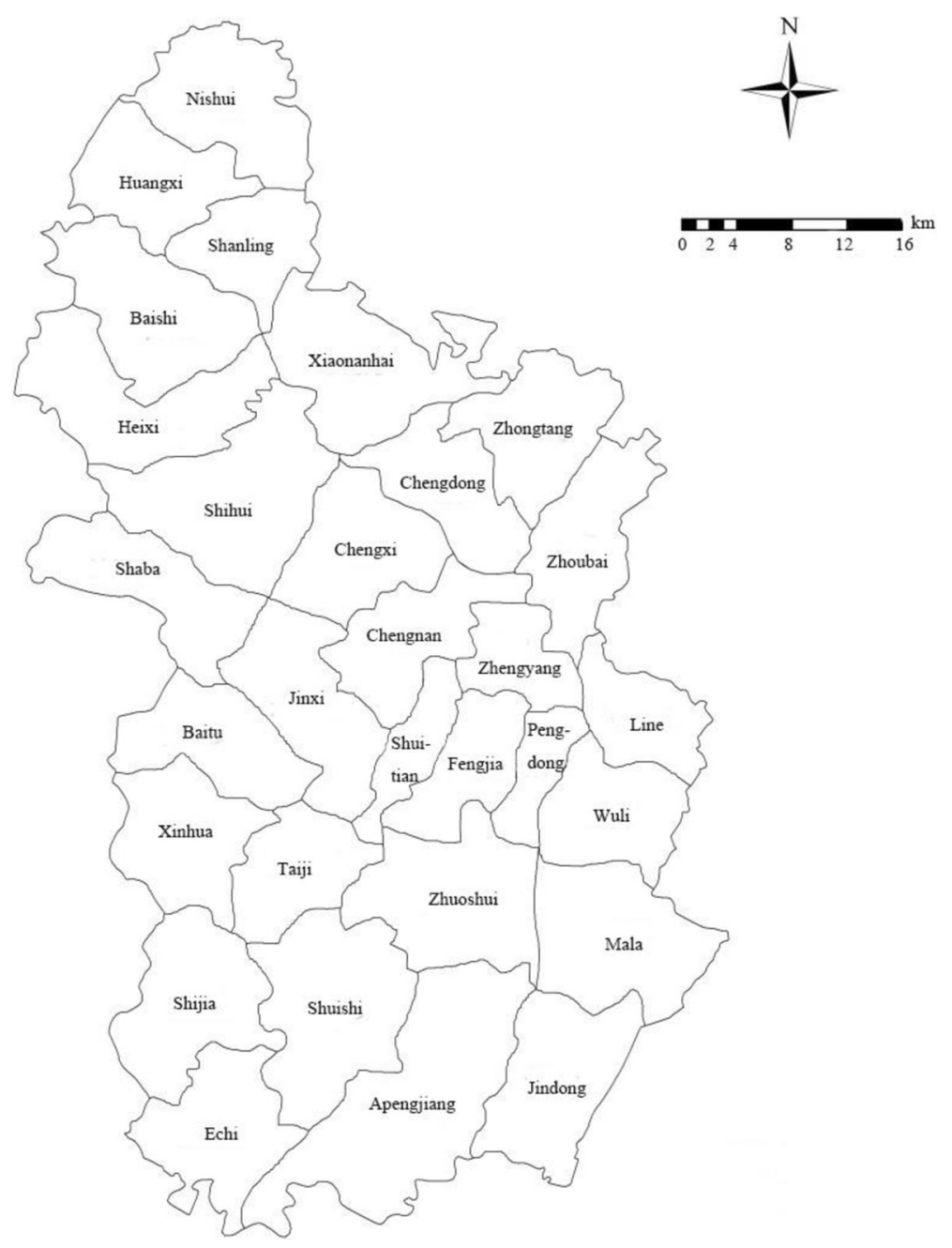

Fig. 1 Qianjiang administrative map

\section{Statistical analysis}

\section{Theil index}

Concentration and spatial variation measures are usually performed by means of a variety of indices, i.e. the Gini index, the Theil index, the concentration index, and Moran's I. Theil index is considered the simplest variation indicator for the reason that it does not depend on any additional parameter [33], hence, we calculated the Theil index for health insurance compensation by person-times and compensation by amounts at the town level to analyze geographic variation in health insurance benefits. Geographic variation was estimated using the following simplified formula:

$$
T=\sum_{i=1}^{n} P_{i} \log \frac{P_{i}}{Y_{i}}
$$

Where $P_{i}$ equals the proportion of the insured population of region $i$ in the whole insured population, and $Y_{i}$ represents the proportion of compensation by persontimes or by amounts of region $i$ in the whole compensation by person-times or by amounts. If $P_{i}=Y_{i}$, then $T_{i}$ equals 0 , which indicates that there is no inequality for this region. If $P_{i}>Y_{i}$, then $T_{i}>0$, his region is not in favor of compensation; the bigger the value, the greater the disadvantage region $i$ suffers. If $P_{i}<Y_{i}$, then $T_{i}<0$, this region is in favor of compensation; the smaller the value, the greater the advantage region $i$ enjoys.

\section{Spatial interpolation analysis}

The geographic distribution of health insurance benefits based on the Theil index values was displayed by the colored choropleth map using the spatial interpolation analysis with the Geographic Information System [34]. With this method, the closer the points are in the space, the more likely it is that these points have similar characteristics. With the spline function, points were interpolated 
into the grid surface, and data of discrete points were converted into continuous surface data.

\section{Multiple linear regression}

In order to clarify the spatial variation of health insurance benefits, the non-spatial regression, ordinary least squares (OLS), was firstly used with the Theil index value as the dependent variable. Considering the study framework of Anderson's healthcare utilization model [35], unit of analysis and data availability, we selected ability of healthcare delivery, healthcare-seeking behavior of the insured, geographical accessibility of healthcare, and economic factors to analyze the potential factors influencing geographic variation of health insurance benefits.

(1)The ability of healthcare delivery was measured by healthcare staff density (the number of healthcare staff per 1000 residents), the density of actual open beds (the number of actual open beds per 1000 residents) and the availability of lower abdominal surgery (available $=1$ ). The number of healthcare staff and actual open beds, as well as the availability of lower abdominal surgery, were investigated using questionnaires for the township health centers. Population for each town was collected through the 2014 Statistical Yearbook of Qianjiang District.

(2)The healthcare-seeking behavior of the insured was computed as the proportion of compensation by person-times in primary healthcare institutions that accounted for the overall compensation by persontimes in each town and the data were collected from the basic health insurance system.

(3) The geographical accessibility of healthcare was estimated based on travel time from the town government to the Qianjiang Central Hospital, which is the best hospital in that district, by car using Google Maps [36, 37].

(4) The town-level economic factor was represented by the per-capita net income at the town level in RMB $(¥)$ in 2013 and was collected from the 2014 Statistical Yearbook of Qianjiang District.

The density of healthcare staff, density of actual open beds, geographical accessibility of healthcare and townlevel economic factor were conducted by standardized normal $\mathrm{Z}$ transformation to eliminate dimension so that data had same caliber.

Moran's I for OLS residuals were tested in order to find the necessity of taking spatial dependencies into consideration. In the current study, it demonstrated that no significant spatial autocorrelation existed (For compensation by person-times as the dependent variable: Moran's $I=-0.021, p=0.397>0.05$; For compensation by amounts as the dependent variable: Moran's $I=-$ $0.049, p=0.387>0.05)$ and there was no need to conduct spatial regression analysis [38, 39].

All maps were displayed using ArcGIS 10.2. Theil index, Moran's I and multiple linear regression analysis were performed using Stata Version 13.0.

\section{Results}

\section{Theil index value}

The Theil index values showed that there was great geographic variation of health insurance benefits in both compensation by person-times and amount, and the geographic variation distribution was divergent for hospitalization types, presented in Table 1 . The total Theil index values for compensation by person-times and amount were up to 0.5886 and 0.7074 respectively. However, the variation resulted from hospitalization between primary healthcare institutions and secondary healthcare institutions were much more severe, Theil index values for compensation by person-times and amount were 2.5028 and 1.8394 in primary healthcare institutions, and 1.1466 and 0.9204 in secondary healthcare institutions. Besides, the numbers of which townships were in favor of health insurance benefits also demonstrated the different distribution, for 18 towns were in favor of compensation by person-times for hospitalization in primary healthcare institutions while the number was only 9 for that in secondary healthcare institutions, and 16 towns were in favor of compensation by amounts for hospitalization in primary healthcare institutions while the number was only 10 for that in secondary healthcare institutions.

\section{Spatially interpolated and geographic variation}

The spatially interpolated surface of health insurance compensation by person-times and amount permits a more visual image of regional patterns of health insurance benefits in Qianjiang. As shown in Fig. 2, the higher the Theil index value, the deeper the color and the more disadvantage experienced by the region. It was obvious that the distribution of health insurance benefits for insured inpatients in primary healthcare institutions was distinctly different from that in secondary healthcare institutions.

For health insurance compensation by person-times as shown in Part A, the deepest colors appeared in remote and broader areas western and southern, including Heixi Town, and the lightest colors district center and along the north-south highways, consisting of Zhoubai, Zhengyang, Fengjia, Pengdong, and Zhuoshui. However, in addition to the similar geographic distribution, there were deep colors in the north of Nishui Town for compensation by amounts. 
Table 1 Theil index values of the compensation number and amount of insured inpatients

\begin{tabular}{|c|c|c|c|c|c|c|c|c|c|c|c|c|c|}
\hline \multirow[t]{2}{*}{ Town } & \multirow{2}{*}{$\begin{array}{l}\text { The } \\
\text { insured }\end{array}$} & \multicolumn{4}{|c|}{ The whole district } & \multicolumn{4}{|c|}{ Primary healthcare institutions } & \multicolumn{4}{|c|}{ Secondary healthcare institutions } \\
\hline & & Number & $T_{p}$ & Amount & $T_{c}$ & Number1 & $T_{p 1}$ & Amount1 & $T_{c l}$ & Number2 & $T_{p 2}$ & Amount2 & $T_{c 2}$ \\
\hline Chengdong & 24,000 & 3543 & 0.0052 & $6,794,882$ & -0.4080 & 712 & 1.7902 & 689,928 & 0.4447 & 2831 & -0.7887 & $6,103,636$ & -0.5267 \\
\hline Chengnan & 19,917 & 2961 & -0.0093 & $5,796,492$ & -0.3921 & 623 & 1.3828 & 419,902 & 0.9714 & 2338 & -0.6451 & $5,377,400$ & -0.5532 \\
\hline Chengxi & 19,800 & 3000 & -0.0459 & $5,174,217$ & -0.1819 & 902 & 0.6486 & 586,300 & 0.3096 & 2098 & -0.4435 & $4,588,326$ & -0.2549 \\
\hline Zhengyang & 13,981 & 2627 & -0.3259 & $4,422,418$ & -0.3889 & 1063 & -0.2405 & 499,610 & -0.0377 & 1564 & -0.3872 & $3,922,512$ & -0.4407 \\
\hline Zhoubai & 23,000 & 4386 & -0.5693 & $6,596,934$ & -0.4202 & 1920 & -0.6053 & 919,680 & -0.3142 & 2466 & -0.5417 & $5,679,198$ & -0.4385 \\
\hline Fengjia & 22,456 & 3777 & -0.2809 & $6,401,660$ & -0.3968 & 1649 & -0.3102 & $1,035,572$ & -0.6191 & 2128 & -0.2584 & $5,366,816$ & -0.3567 \\
\hline Xiaonanhai & 8569 & 1377 & -0.0690 & $1,760,066$ & 0.1225 & 826 & -0.3458 & 409,696 & -0.2664 & 551 & 0.2255 & $1,350,501$ & 0.2119 \\
\hline Line & 13,122 & 2175 & -0.1454 & $3,056,112$ & 0.0268 & 1141 & -0.3976 & 621,845 & -0.3967 & 1034 & 0.0851 & $2,434,036$ & 0.1159 \\
\hline Apengjiang & 25,025 & 3779 & -0.0499 & $5,560,764$ & 0.1659 & 1880 & -0.4013 & 825,320 & 0.1284 & 1899 & 0.2543 & $4,736,106$ & 0.1721 \\
\hline Shihui & 19,718 & 2709 & 0.1425 & $4,338,713$ & 0.1496 & 1174 & 0.1310 & 709,096 & -0.0653 & 1535 & 0.1513 & $3,630,275$ & 0.1886 \\
\hline Heixi & 20,202 & 2145 & 0.6538 & $3,840,949$ & 0.4412 & 705 & 1.1869 & 331,350 & 1.4800 & 1440 & 0.3286 & $3,509,280$ & 0.3078 \\
\hline Huangxi & 12,505 & 1466 & 0.2839 & $2,370,757$ & 0.2766 & 761 & 0.0564 & 522,046 & -0.2234 & 705 & 0.4895 & $1,848,510$ & 0.3874 \\
\hline Nishui & 12,848 & 1624 & 0.1973 & $2,057,001$ & 0.4960 & 904 & -0.1239 & 327,248 & 0.3897 & 720 & 0.5105 & $1,729,440$ & 0.5154 \\
\hline Jinxi & 13,659 & 2049 & -0.0184 & $3,326,494$ & -0.0316 & 993 & -0.1753 & 805,323 & -0.7039 & 1056 & 0.1140 & $2,520,672$ & 0.1275 \\
\hline Mala & 15,882 & 2565 & -0.1357 & $3,825,077$ & -0.0195 & 1408 & -0.5112 & 737,792 & -0.4492 & 1157 & 0.2246 & $3,086,876$ & 0.0680 \\
\hline Zhuoshui & 16,377 & 3000 & -0.3412 & $5,230,374$ & -0.4709 & 1205 & -0.2294 & 718,180 & -0.3712 & 1795 & -0.4209 & $4,512,630$ & -0.4875 \\
\hline Shijia & 13,876 & 1922 & 0.0892 & $3,121,151$ & 0.0755 & 869 & 0.0238 & 485,771 & -0.0096 & 1053 & 0.1410 & $2,635,659$ & 0.0905 \\
\hline Echi & 12,120 & 1410 & 0.2842 & $2,267,085$ & 0.2839 & 625 & 0.2505 & 288,125 & 0.4492 & 785 & 0.3104 & $1,978,985$ & 0.2579 \\
\hline Zhongtang & 14,620 & 1822 & 0.2447 & $3,268,018$ & 0.0885 & 606 & 0.6136 & 345,420 & 0.5506 & 1216 & 0.0178 & $2,922,048$ & 0.0227 \\
\hline Pengdong & 8178 & 1715 & -0.2782 & $2,138,677$ & -0.0757 & 984 & -0.5069 & 423,120 & -0.3173 & 731 & -0.0475 & $1,715,657$ & -0.0259 \\
\hline Shaba & 14,334 & 2188 & -0.0436 & $3,777,906$ & -0.1436 & 733 & 0.3079 & 400,951 & 0.3038 & 1455 & -0.2611 & $3,377,055$ & -0.2077 \\
\hline Baishi & 16,911 & 1826 & 0.5196 & $3,435,822$ & 0.2598 & 675 & 0.7720 & 497,475 & 0.2753 & 1151 & 0.3513 & $2,938,503$ & 0.2572 \\
\hline Shanling & 9468 & 1264 & 0.0949 & $1,535,344$ & 0.3537 & 732 & -0.1783 & 333,792 & -0.0130 & 532 & 0.3737 & $1,201,788$ & 0.4340 \\
\hline Taiji & 12,045 & 1739 & 0.0288 & $2,790,462$ & 0.0309 & 827 & -0.0874 & 380,420 & 0.1126 & 912 & 0.1250 & $2,410,416$ & 0.0173 \\
\hline Shuitian & 10,035 & 1229 & 0.1850 & $2,084,185$ & 0.1326 & 452 & 0.3398 & 208,824 & 0.5022 & 777 & 0.0823 & $1,875,678$ & 0.0812 \\
\hline Baitu & 10,962 & 1294 & 0.2415 & $1,863,312$ & 0.3591 & 709 & -0.0157 & 432,490 & -0.1354 & 585 & 0.4878 & $1,430,910$ & 0.4726 \\
\hline Jindong & 11,152 & 1499 & 0.1044 & $2,390,102$ & 0.1132 & 783 & -0.1052 & 461,187 & -0.1889 & 716 & 0.2951 & $1,928,904$ & 0.1746 \\
\hline Wuli & 11,029 & 1806 & -0.1091 & $2,555,192$ & 0.0282 & 970 & -0.3464 & 462,690 & -0.2023 & 836 & 0.1133 & $2,092,508$ & 0.0732 \\
\hline Shuishi & 10,763 & 1615 & -0.0148 & $2,065,960$ & 0.2250 & 864 & -0.2422 & 343,008 & 0.0912 & 751 & 0.1975 & $1,722,794$ & 0.2499 \\
\hline Xinhua & 8700 & 1365 & -0.0498 & $2,050,697$ & 0.0076 & 684 & -0.1781 & 255,132 & 0.1443 & 681 & 0.0621 & $1,795,116$ & -0.0135 \\
\hline total & 445,254 & 65,877 & 0.5886 & $105,896,823$ & 0.7074 & 28,379 & 2.5028 & $15,477,293$ & 1.8394 & 37,498 & 1.1466 & $90,422,235$ & 0.9204 \\
\hline
\end{tabular}

Note: Number, Number1, Number2, the compensation number; $T_{p}, T_{p 1}, T_{p 2}$, the Theil index value of the compensation by person-times. Amount, Amount1, Amount2, the compensation by amounts; $T_{c}, T_{c 1}, T_{c 2}$, the Theil index value of the compensation by amounts. The insured, the number of the insured population in the Qianjiang District

For primary healthcare institutions shown in Part B, the deeper colors were distributed west of Heixi and around the district center, including Zhongtang, Chengdong and Chengnan, and the lightest colors were distributed across most of this district for health insurance benefits.

By contrast, for secondary healthcare institutions as shown in Part $\mathrm{C}$, there were deeper colors in the remote and border areas northwestern, western and southern for the compensation by person-times and amounts. The lightest colors presented a more concentrated distribution in the eastern areas, which were seen around the district center and along the north-south highways.

\section{Results of regression analysis}

As shown in Table 2, the per-capita net income at the town level that measured economic factor had significant negative effect on Theil index values of both compensation by person-times and compensation by amounts, which demonstrated that regions considerably richer enjoyed more healthcare insurance benefits. This finding aligns with most prior studies $[11,40]$.

Patients' healthcare-seeking behavior represented by the proportion of hospitalization admissions in primary health centers including township health centers and community health center, was positively related 


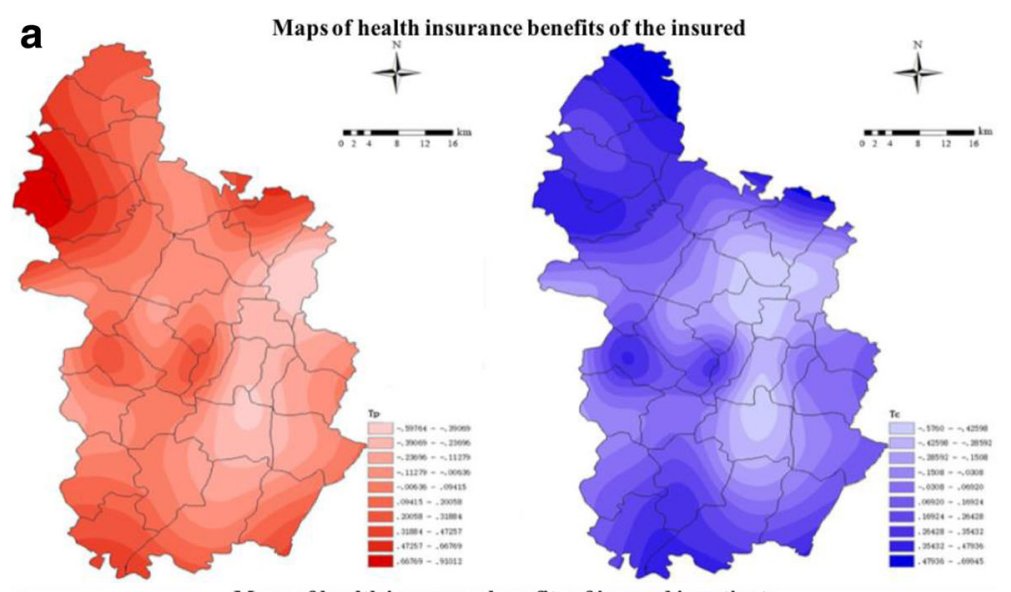

b

Maps of health insurance benefits of insured inpatients

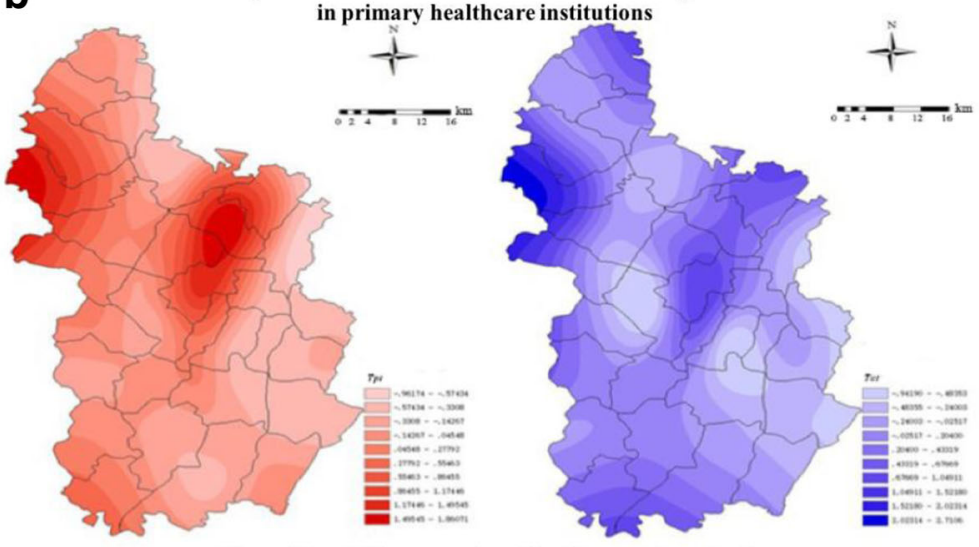

Maps of health insurance benefits of insured inpatients

C

in secondary healthcare institutions

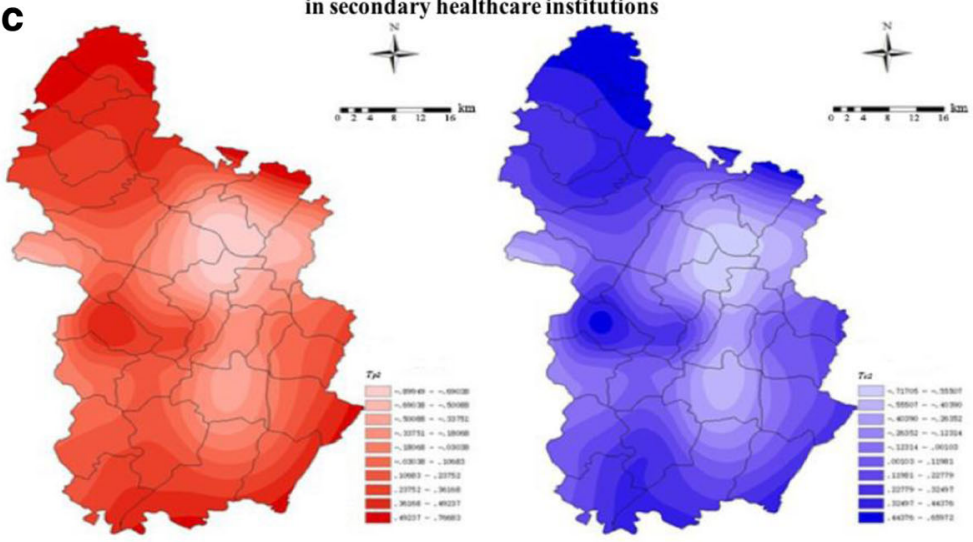

Fig. 2 Theil index of health insurance benefits.

Note: Panel abc describe the maps of health insurance benefits of the whole insured inpatients, the insured inpatients in primary healthcare institutions, and the insured inpatients in secondary healthcare institutions, respectively. The red maps in the left-side represent health insurance benefits of compensation by persontimes, the blue maps in the right-side represent health insurance benefits of compensation by amounts

to benefits in compensation by person-times, while, this kind of relationship could not be testified in compensation by amounts. On the contrary, the significantly negative coefficient for the standardized geographical accessibility of healthcare in the OLS model demonstrated that the central area where most of the secondary healthcare institutions and both political and economic center located had an advantage in health insurance compensation by amounts, while, no such relationship could be found in compensation by person-times. It testified that the central region consumed more health insurance resources than the 
Table 2 Regression coefficients and standard errors

\begin{tabular}{lcc}
\hline Variables & $T_{p}$ coefficients $(S E)$ & $T_{c}$ coefficients (SE) \\
\hline ZStaff & $-0.037(0.040)$ & $-0.027(0.048)$ \\
ZBed & $0.006(0.034)$ & $-0.016(0.041)$ \\
Availability & $0.054(0.078)$ & $0.013(0.093)$ \\
SeekBeha & $-0.088^{* * *}(0.015)$ & $-0.025(0.017)$ \\
ZAccessibility & $0.063(0.042)$ & $0.122^{* *}(0.050)$ \\
ZEconomic & $-0.092^{* *}(0.04)$ & $-0.110^{* *}(0.049)$ \\
Constant & $0.593^{* * *}(0.101)$ & $0.186(0.121)$ \\
\hline
\end{tabular}

Note: ${ }^{* *} p<0.05,{ }^{* * *} p<0.001$; SE standard error, ZStaff the standardized density of healthcare staff, ZBed the standardized density of actual open beds, Availability the availability of lower abdominal surgery, SeekBeha the healthcare-seeking behavior of the insured, ZAccessibility the standardized geographical accessibility of healthcare, ZEconomic The town-level economic factor

remote areas did, which actually aligns with our observation that the residents in central part, were more likely to hospitalize in secondary hospital where the expense were much higher than the average.

The findings showed that the ability of healthcare delivery represented by the density of healthcare staff, actual open beds and the availability of lower abdominal surgery was an inexplicable explanatory variable for health insurance benefits both in compensation by person-times and amount.

The two OLS models had comparatively high goodness of fit [41]. $\mathrm{R}^{2}$ were 0.742 and 0.656 for compensation by person-times and amount respectively. The regression residuals for each model obeyed the normal distribution (for Tp: $p=0.200>0.05$; for Tc: $p=0.201>$ $0.05)$. Collinearity diagnosis results showed that the Variance inflation coefficient (VIF) for each independent variable was smaller than 10 , which demonstrated the little possibility of collinearity.

\section{Discussion}

In this study, we found that towns had different Theil index values of health insurance benefits and that there was great geographic variation in health insurance benefits. Furthermore, economic factor had a significant positive influence on health insurance benefits in Qianjiang District.

Our results clearly revealed the characteristics of geographic variation in health insurance benefits. There was smaller geographic variation in compensation by persontimes than in compensation by amounts for all the insured inpatients. However, for primary healthcare institutions, the geographic distribution of variation in compensation by person-times and amounts were almost the same: insurance benefits were sparse in the western areas and district centers for primary healthcare institutions. In contrast, for secondary healthcare institutions, insurance benefits were concentrated in the district center and the regions along the north-south highways, which was nearly the same as the geographic distribution of the variation in health insurance benefits in the whole district. The distribution of geographic variation proved the necessity of exploring the factors from the perspective of patient characteristics and supplier characteristics.

Our results demonstrated that economic factor was positively associated with the health insurance benefits significantly. The distribution of income within society is one of the main factors affecting health and its services $[42,43]$, and those in the high-income group may be more likely to follow doctors' recommendations, seek and use inpatient services, and may benefit more from central subsidies than the low-income group under the same basic health insurance [44]. Generally, the residents in and around the district center have higher incomes. Therefore, residents located in the district center may have more healthcare service utilization and benefit more from the same basic health insurance than others.

However, the healthcare-seeking behavior of the insured was only negatively associated with the Theil index values of health insurance compensation by persontimes. This may be in accordance with the focus on primary care delivery; the "tiered health service delivery" and the reimbursement strategy of basic health insurance are inclined toward primary healthcare institutions in the rural healthcare system in China. Nevertheless, the percentage was not associated with the Theil index value of compensation by amounts.

Our results demonstrated that geographical accessibility of Qianjiang Central Hospital medical services led to geographic variation in health insurance benefits in the perspective of compensation by amounts. Actually, it is consistent with our observation that residents in and around the central part of this district and near the northsouth highways may experience more convenient traffic, which leads to less travel time and considerably better healthcare services provided by the secondary healthcare institutions, hence resulting in more utilization of healthcare services of high expenses. The association between both the road distribution and traffic convenience and the geographical accessibility of social resources has already been demonstrated [45], so has the relationship between geographical accessibility and healthcare-seeking behavior and services utilization [46, 47]. However, the geographic accessibility has insignificant effect on health insurance benefits in compensation by person-times, for the reason that the geographic accessibility in this study was represented by the shorted time to arrive in Qianjiang Central Hospital instead of the nearest healthcare service, which is distinctly different from the definition in prior studies [46, 47]. 
However, we found no statistical association between three indicators of healthcare delivery and geographic variation in health insurance benefits. This may have been because we selected only three typical indicators to represent healthcare delivery at the town level, and we did not have enough evidence to guarantee that these indicators could measure healthcare service delivery appropriately, accurately, and effectively in this district.

This study has several potential limitations. First, individual and family information of the insured inpatients was ignored, for their demographic characteristics, socioeconomic characteristics, diseases type or disease severity were not taken into consideration. Second, geographic variation in health insurance benefits was analyzed at the township level in this study. Heterogeneity of towns were ignored as township is the smallest administrative unit in China containing its own area, geography and population. Zip code [48] and healthcare service unit $[49,50]$ need to be investigated in our further study as they were selected in some previous studies. Finally, no pre-after analysis was conducted in the current study which led to the unavailability of demonstrating the effect of integration of the two kinds of health insurance on geographic variation of health insurance benefits.

Despite the above limitations, our findings are of great importance to health insurance policymaking. The concept that: "coverage should be for everyone", one of the features of universal health coverage, is built on the foundation that good healthcare services be available from the health resources located close to people, regardless of income level, without unaffordable out-of-pocket payments [51]. When combining the NRCM and URMIS, we need to attach great importance to the system-wide or districtwide geographic variation in health insurance benefits and the contributing factors, namely, the geographic accessibility of healthcare and economic factors.

\section{Conclusion}

This study was the first to examine geographic variation in health insurance benefits in China. In this study, the Theil index values were differed by town, and there was great geographic variation at the town level. Moreover, the geographic accessibility of healthcare, healthcare-seeking behavior and economic factors may be of great significance. The next step in our further research may be to expand the sample areas under the pilot of the integration of the NCMS and URBMI.

\footnotetext{
Abbreviations

Availability: the availability of lower abdominal surgery; NCMS: New Cooperative Medical Scheme; OLS: Ordinary Least Squares; SeekBeha: the healthcare-seeking behavior of the insured; UEBMI: Urban Employee Basic Medical Insurance; URBMI: Urban Resident Basic Medical Insurance; URRBMI: Urban and Rural Resident Basic Medical Insurance Scheme; ZAccessibility: the standardized geographical accessibility of healthcare; ZBed: the standardized density of actual open beds; ZEconomic: The townlevel economic factor; ZStaff: the standardized density of healthcare staff
}

\section{Acknowledgements}

This project proceeded with the help of local administrative authorities: the Qianjiang Health and Family Planning Bureau and the Medical Insurance Department of the Qianjiang Human Resource and Social Security Bureau.

\section{Funding}

This study was funded by National Natural Science Foundation of China (71403092), the China Medical Board (11-069), and the China Postdoctoral Science Foundation (2014 M562035)

\section{Availability of data and materials}

The datasets generated and analyzed during the current study are not publicly available but are available from the corresponding author upon reasonable request.

\section{Authors' contributions}

YW and TY planned the study, conducted the analyses, and interpreted the results. TY and LZ conceptualized and led the main study, helped interpret the results, wrote sections of the manuscript, and revised the manuscript. XL and YW conducted data analysis and assisted with the presentation and interpretation of data. All have given final approval of the version of the manuscript to be published.

\section{Ethics approval and consent to participate}

All research methods and investigation tools in this study were approved by the Ethics Committee of Tongji Medical College, Huazhong University of Science and Technology (IORG No: IORG0003571). All participants gave written informed consent for participation in this study, provided consent before filling out the questionnaire, and consented to the publication of the data.

\section{Consent for publication}

Not applicable

\section{Competing interests}

The authors declare that they have no competing interests.

\section{Publisher's Note}

Springer Nature remains neutral with regard to jurisdictional claims in published maps and institutional affiliations.

Received: 3 May 2017 Accepted: 16 January 2018

Published online: 05 February 2018

\section{References}

1. Richardson E, Roberts B, Sava V, Menon R, McKee M. Health insurance coverage and health care access in Moldova. Health Policy Plan. 2012;27: 204-12.

2. Garcia-Subirats I, Vargas I, Mogollon-Perez AS, De Paepe P, da Silva MR, Unger JP, Vazquez ML. Barriers in access to healthcare in countries with different health systems. A cross-sectional study in municipalities of central Colombia and north-eastern Brazil. Soc Sci Med. 2014;106:204-13.

3. DiPietro B, Klingenmaier L. Achieving public health goals through Medicaid expansion: opportunities in criminal justice, homelessness, and behavioral health with the patient protection and affordable care act. Am J Public Health. 2013;103(Suppl 2):e25-9.

4. Organization WH: World Health Report 2010: Health systems financing- The Path to universal coverage.

5. Knaul FM, Gonzalez-Pier E, Gomez-Dantes O, Garcia-Junco D, ArreolaOrnelas H, Barraza-Llorens M, Sandoval R, Caballero F, Hernandez-Avila M, Juan $M$, et al. The quest for universal health coverage: achieving social protection for all in Mexico. Lancet. 2012;380:1259-79.

6. Saksena P, Antunes AF, Xu K, Musango L, Carrin G. Mutual health insurance in Rwanda: evidence on access to care and financial risk protection. Health Policy. 2011;99:203-9.

7. Wang HQ, Liu ZH, Zhang YZ, Luo ZJ. Integration of current identity-based district-varied health insurance schemes in China: implications and challenges. Front Med. 2012;6:79-84.

8. Fu R, Wang Y, Bao H, Wang Z, Li Y, Su S, Liu M. Trend of urban-rural disparities in hospital admissions and medical expenditure in China from 2003 to 2011. PLoS One. 2014;9:e108571. 
9. Pan XF, Xu J, Meng Q. Integrating social health insurance systems in China Lancet. 2016;387:1274-5.

10. Kim AM, Park JH, Kang S, Hwang K, Lee T, Kim Y. The effect of geographic units of analysis on measuring geographic variation in medical services utilization. J Prev Med Public Health. 2016;49:230-9.

11. Onyeonoro UU, Ogah OS, Ukegbu AU, Chukwuonye II, Madukwe OO, Moses AO. Urban-rural differences in health-care-seeking pattern of residents of Abia state, Nigeria, and the implication in the control of NCDs. Health Serv Insights. 2016;9:29-36.

12. Haynes RM, Bentham CG. The effects of accessibility on general practitioner consultations, out-patient attendances and in-patient admissions in Norfolk, England. Soc Sci Med. 1982;16:561-9.

13. Pathman DE, Ricketts TC 3rd, Konrad TR. How adults' access to outpatient physician services relates to the local supply of primary care physicians in the rural southeast. Health Serv Res. 2006:41:79-102.

14. Erlyana E, Damrongplasit KK, Melnick G. Expanding health insurance to increase health care utilization: will it have different effects in rural vs. urban areas? Health Policy. 2011;100:273-81.

15. Mullee M, De Stavolla B, Romanengo M, Coleman MP. Geographical variation in breast cancer survival rates for women diagnosed in England between 1992 and 1994. Br J Cancer. 2004;90:2153-6.

16. Tseng JH, Merchant E, Tseng MY. Effects of socioeconomic and geographic variations on survival for adult glioma in England and Wales. Surg Neurol. 2006;66:258-63.

17. Eaker S, Dickman PW, Hellstrom V, Zack MM, Ahlgren J, Holmberg L, Grp UBC. Regional differences in breast cancer survival despite common guidelines. Cancer Epidemiol Biomark Prev. 2005;14:2914-8.

18. Henry KA, Niu XL, Boscoe FP. Geographic disparities in colorectal cancer survival. Int J Health Geogr. 2009;8

19. Pickle LW, Gillum RF. Geographic variation in cardiovascular disease mortality in US blacks and whites. J Natl Med Assoc. 1999;91:545-56.

20. Goodwin JS, Freeman JL, Freeman D, Nattinger AB. Geographic variations in breast cancer mortality: do higher rates imply elevated incidence or poorer survival? Am J Public Health. 1998:88:458-60.

21. Mick SS, Lee SY. Are there need-based geographical differences between international medical graduates and U.S. medical graduates in rural U.S. counties? J Rural Health. 1999;15:26-43.

22. Towne SD Jr, Smith ML, Ory MG. Geographic variations in access and utilization of cancer screening services: examining disparities among American Indian and Alaska native elders. Int J Health Geogr. 2014;13:18.

23. Legler J, Breen N, Meissner H, Malec D, Coyne C. Predicting patterns of mammography use: a geographic perspective on national needs for intervention research. Health Serv Res. 2002;37:929-47.

24. Nigam A. The effects of institutional change on geographic variation and health services use in the USA. Soc Sci Med. 2012;74:323-31.

25. Rosenthal T. Geographic Variation in Health Care. Annu Rev Med. 2012;63: 493-509.

26. Lavergne MR, Barer M, Law MR, Wong ST, Peterson S, McGrail K. Examining regional variation in health care spending in British Columbia, Canada. Health Policy. 2016;120:739-48.

27. Newhouse JP, Garber AM. Geographic variation in health care spending in the United States: insights from an Institute of Medicine report. JAMA. 2013; 310:1227-8.

28. Harounian JA, Schaefer E, Schubart J, Carr MM. Pediatric Posttonsillectomy hemorrhage: demographic and geographic variation in health care costs in the United States. Otolaryngol Head Neck Surg. 2016;155:289-94.

29. Collado M. Patient health causes substantial portion of geographic variation in Medicare costs. Find Brief. 2013;16:1-4.

30. Zhang Y, Baicker K, Newhouse JP. Geographic variation in Medicare drug spending. N Engl J Med. 2010;363:405-9.

31. Zhang Y, Baicker K, Newhouse JP. Geographic variation in the quality of prescribing. N Engl J Med. 2010;363:1985-8.

32. Vogt $V$, Siegel $M$, Sundmacher $L$. Examining regional variation in the use of cancer screening in Germany. Soc Sci Med. 2014;110:74-80.

33. Tao Y, Henry K, Zou Q, Zhong X. Methods for measuring horizontal equity in health resource allocation: a comparative study. Health Econ Rev. 2014;4:10.

34. Henriksson S, Hagberg J, Backstrom M, Persson I, Lindstrom G. Assessment of PCDD/fs levels in soil at a contaminated sawmill site in Sweden - a GIS and PCA approach to interpret the contamination pattern and distribution. Environ Pollut. 2013;180:19-26.
35. Andersen R, Newman JF. Societal and individual determinants of medical care utilization in the United States. Milbank Mem Fund Q Health Soc. 1973; 51:95-124.

36. Stentzel U, Piegsa J, Fredrich D, Hoffmann W, van den Berg N. Accessibility of general practitioners and selected specialist physicians by car and by public transport in a rural region of Germany. BMC Health Serv Res. 2016;16:587.

37. Gao F, Kihal W, Le Meur N, Souris M, Deguen S. Assessment of the spatial accessibility to health professionals at French census block level. Int J Equity Health. 2016;15

38. Gatrell AC, Bailey TC. Interactive spatial data analysis in medical geography. Soc Sci Med. 1996:42:843-55.

39. Cressie NAC: Statistics for spatial data. Rev. edn. New York: Wiley; 1993.

40. Kim MJ, Lee H, Kim EH, Cho MH, Shin DW, Yun JM, Shin JH. Disparity in health screening and health utilization according to economic status. Korean J Fam Med. 2017:38:220-5.

41. Cohen J, Cohen P: Applied multiple regression/correlation analysis for the behavioral sciences. Hillsdale, N.J. New York: Lawrence Erlbaum Associates: distributed by Halsted Press Division of John Wiley; 1975.

42. Kawachi I, Kennedy BP. Income inequality and health: pathways and mechanisms. Health Serv Res. 1999;34:215-27.

43. Bergner L, Yerby AS. Low income and barriers to use of health services. $N$ Engl J Med. 1968;278:541-6.

44. Yu BR, Meng QY, Collins C, Tolhurst R, Tang SL, Yan F, Bogg L, Liu XY. How does the new cooperative medical scheme influence health service utilization? A study in two provinces in rural China. BMC Health Serv Res. 2010;10

45. Munoz UH, Kallestal C. Geographical accessibility and spatial coverage modeling of the primary health care network in the Western Province of Rwanda. Int J Health Geogr. 2012;11

46. Gabrysch S, Campbell OMR. Still too far to walk: literature review of the determinants of delivery service use. Bmc Pregnancy And Childbirth. 2009;9

47. Padilla CM, Kihal-Talantikit W, Perez S, Deguen S. Use of geographic indicators of healthcare, environment and socioeconomic factors to characterize environmental health disparities. Environ Health. 2016:15

48. Angier H, Likumahuwa S, Finnegan S, Vakarcs T, Nelson C, Bazemore A, Carrozza M, DeVoe JE. Using geographic information systems (GIS) to identify communities in need of health insurance outreach: an OCHIN practice-based research network (PBRN) report. J Am Board Fam Med. 2014:27:804-10.

49. Perry DC, Bruce CE, Pope D, Dangerfield P, Platt MJ, Hall AJ. Legg-calve-Perthes disease in the UK: geographic and temporal trends in incidence reflecting differences in degree of deprivation in childhood. Arthritis Rheum. 2012; 64:1673-9.

50. McKernan SC, Kuthy RA, Hanley PF, Jones MP, Momany ET, McQuistan MR, Damian PC. Geographic variation of dental utilization among low income children. Health \& Place. 2015;34:150-6.

51. Evans DB, Hsu J, Boerma T. Universal health coverage and universal access. Bull World Health Organ. 2013;91:546.

\section{Submit your next manuscript to BioMed Central and we will help you at every step:}

- We accept pre-submission inquiries

- Our selector tool helps you to find the most relevant journal

- We provide round the clock customer support

- Convenient online submission

- Thorough peer review

- Inclusion in PubMed and all major indexing services

- Maximum visibility for your research

Submit your manuscript at www.biomedcentral.com/submit
Biomed Central 